\title{
Perception of the length of an object through dynamic touch is invariant across changes in the medium
}

\author{
Madhur Mangalam $^{1}$ (D) - Sophie A. Barton ${ }^{1} \cdot$ Jeffrey B. Wagman $^{2} \cdot$ Dorothy M. Fragaszy $^{1}$ • \\ Karl M. Newell ${ }^{3}$
}

Published online: 24 August 2017

(C) The Psychonomic Society, Inc. 2017

\begin{abstract}
Rotational inertia - a mechanical quantity that describes the differential resistance of an object to angular acceleration in different directions-has been shown to support perception of the properties of that object through dynamic touch (wielding). The goal of the present study was to examine if perception of the length of an object through dynamic touch depends on its rotational inertia, independent of the medium in which it is wielded. The participants $(n=14)$ wielded 12 different objects held in air or completely immersed in water and reported perceived lengths of those objects. Each object consisted of a rod of a particular density with a particular number of stacked steel rings attached at a particular location along its length. Perceived length was invariant across medium. In addition, a singlevalued function of the major eigenvalue, $I_{1}$, and the minor eigenvalue, $I_{3}$, of the rotational inertia, $I$, of the 12 objects predicted the perceived lengths of those objects in both air and water, and the perceived lengths were invariant across the two media. These results support the hypothesis that the informational support for perception of the length of an object through dynamic touch is invariant across changes in the medium.
\end{abstract}

Keywords Embodied perception · Haptics · Perception and action

Madhur Mangalam

madhur.mangalam@uga.edu

1 Department of Psychology, University of Georgia, Athens, GA, USA

2 Department of Psychology, Illinois State University, Normal, IL, USA

3 Department of Kinesiology, University of Georgia, Athens, GA, USA
Individuals wielding an object in their hand can perceive the length, width, and shape of that object (exteroception), the orientation of that object in their hand (exproprioception), and their hand's location on that object (proexteroception; Shaw, 2001; Turvey \& Fonseca, 2014). These capabilities involve effortfully manipulating an object and thus are collectively termed "dynamic touch" (Carello \& Turvey, 2000; Turvey, 1996; Turvey \& Carello, 2011). Dynamic touch is unique among perceptual modalities in that the information generated by wielding an object is reciprocally used to guide the manipulation of that object.

Movements of an object wielded about any given body joint are rotational. The rotational dynamics of a wielded object generates haptic information through tissue deformation. Mass is the resistance of an object to translational acceleration; rotational inertia is the resistance of an object to rotational acceleration. The torque, $\tau$, required to produce a given angular acceleration, $\omega$, about an axis of rotation is thus a function of rotational inertia, $I$. Rotational inertia is represented as $\mathrm{ML}^{2}$, where $\mathrm{M}$ denotes mass and $\mathrm{L}$ denotes the distribution of mass with respect to an axis of rotation.

The farther the concentration of mass of an object from the axis of rotation, the greater its rotational inertia. For example, while playing baseball, the batter grasps a bat at its thin end (the handle) and swings it with its thick end (the barrel) far from his or her hands. Alternatively, the batter can grasp the bat at its thick end and swing it with its thin end far from his or her hands. Such reversal of the grasp does not alter the bat's length, shape, or mass, but it alters its rotational inertia. Therefore, the batter needs to produce greater muscular torque to swing a bat grasped at its thin end than a bat grasped at its thick end due to a greater rotational inertia in the former case than the latter.

Rotational inertia has been shown to support perception of the properties of an object through dynamic touch (see Turvey 
\& Carello, 2011, for a review). The differential resistance of an object to rotational acceleration in different directions can be quantified in a $3 \times 3$ matrix known as the inertia tensor. The eigenvectors $e_{1}, e_{2}$, and $e_{3}$ of the inertia tensor describe the symmetry axes of the hand-object system about which the mass is distributed evenly (see Fig. 1); $e_{1}, e_{2}$, and $e_{3}$ specify the orientation of the object (Pagano \& Turvey, 1992; Turvey, Burton, Pagano, Solomon, \& Runeson, 1992). The eigenvalues of the inertia tensor $I_{1}, I_{2}$, and $I_{3}$ describe the resistance of an object to rotation about the symmetry axes (see Fig. 1). The largest and the smallest eigenvalues, $I_{1}$ and $I_{3}$, specify the length and width, respectively, of the object (Fitzpatrick, Carello, \& Turvey, 1994; Turvey, Burton, Amazeen, Butwill, \& Carello, 1998) $)^{1}$. The ratio of $I_{1}$ and $I_{3}$ specifies the shape of the object (Burton, Turvey, \& Solomon, 1990).

Individuals can perceive the length of an object through dynamic touch independent of the location of the grasp along the length of that object (Cooper, Carello, \& Turvey, 2000; Pagano, Kinsella-Shaw, Cassidy, \& Turvey, 1994; Solomon, Turvey, \& Burton, 1989) and when wielding it with minimal movement (Burton \& Turvey, 1990; Carello, Fitzpatrick, Domaniewicz, Chan, \& Turvey, 1992). Moreover, they can perceive the whole or partial length of an object independent of whether the object is wielded with the hand, the foot, the torso, or the head (Hajnal, Fonseca, Harrison, Kinsella-Shaw, \& Carello, 2007; Hajnal, Fonseca, Kinsella-Shaw, et al., 2007; Palatinus, Carello, \& Turvey, 2011; Wagman, Langley, \& Higuchi, 2017). Furthermore, individuals can also perceive the length of a rod by wielding it with another rod (Peck, Jeffers, Carello, \& Turvey, 1996).

Air and water are the two primary media in which organisms move their bodies to interact with the objects in their environment (Denny, 1993; Gibson, 1966, 1979). The rotational inertia of an object and the upthrust and the drag exerted by the medium together determine the torque required to wield that object in water. The drag, $D$, is a function of the projected surface area, $A_{\mathrm{p}}$, of the object and the medium's density. The densities of air and water are 1.2 $\mathrm{g} / \mathrm{cm}^{3}$ and $998.2 \mathrm{~g} / \mathrm{cm}^{3}$, respectively, at $20^{\circ} \mathrm{C}$ ambient temperature, $D_{\text {air }}=1.2 \mathrm{~A}_{\mathrm{p}}$ and $D_{\text {water }}=998.2 A_{\mathrm{p}}$, implying that the torque required to wield an object is greater in water than in air. However, the torque required to wield an object in water additionally depends on the density of that object, $\rho_{\text {rod, }}$ in relation to the density of water, $\rho_{\text {water, }}$, or the specific gravity of the object.

The relationship between the specific gravity of a rod and torque required to wield that rod horizontally in air and water, respectively, is shown in Fig. 2. When the density of the rod relative to the density of water is between 0 and $1\left(0.00<\rho_{\text {rod }} /\right.$

\footnotetext{
${ }^{1}$ Although it may be possible to infer the exact length of a rod by wielding it, doing so would require either knowing or inferring several other properties (e.g., density, homogeneity, and grasp position).
}

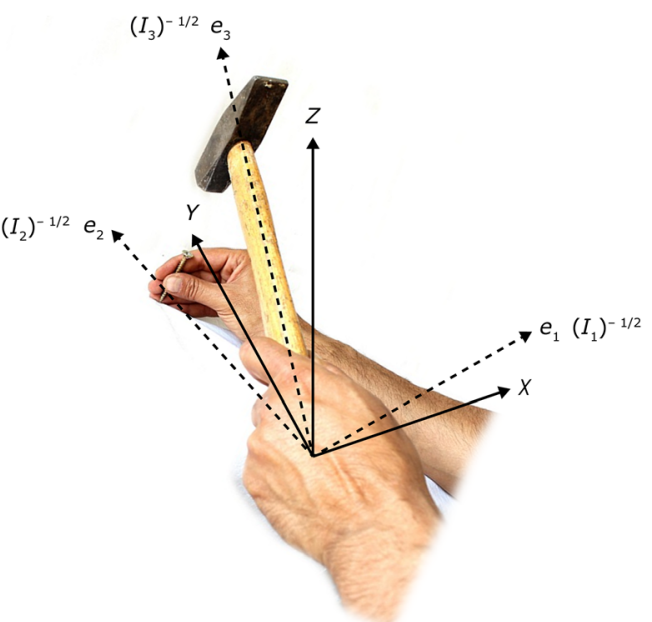

Fig. 1 Eigenvalues $\left(I_{1}, I_{2}\right.$, and $\left.I_{3}\right)$ and eigenvectors $\left(e_{1}, e_{2}\right.$, and $\left.e_{3}\right)$ of the inertia tensor of the hand-object system

$\rho_{\text {water }}<1.00$ ), then $\tau<0$; that is, there is net upward torque on the rod in water. When this value is between 0 and $0.5(0.00<$ $\left.\rho_{\text {rod }} / \rho_{\text {water }}<0.50\right)$, then $\left|\tau_{\text {water }}\right|<\left|\tau_{\text {air }}\right|$; that is, the net upward torque in water is larger in magnitude than the downward torque it experiences in air (see Zone 1 in Fig. 2). When this value equals $0.5\left(\rho_{\text {rod }} / \rho_{\text {water }}=0.50\right)$, then $\left|\tau_{\text {water }}\right|=\left|\tau_{\text {air }}\right|$; that is, the net upward torque in water is equal in magnitude to the downward torque in air (see Fig. 2). When this value is between 0.50 and $1.00\left(0.50<\rho_{\text {rod }} / \rho_{\text {water }}<1.00\right)$, then $\left|\tau_{\text {water }}\right|<$ $\left|\tau_{\text {air }}\right|$; that is, the net upward torque in water is smaller in magnitude than the downward torque in air (see Zone 2 in Fig. 2$)$. When this value is equal to $1.0\left(\rho_{\text {rod }} / \rho_{\text {water }}=1.00\right), \tau$ water $=0$, then there is zero torque in water (see Fig. 2). When this value is greater than $1.0\left(\rho_{\text {rod }} / \rho_{\text {water }}>1.00\right)$, then $\tau_{\text {water }}>$ 0 ; that is, the net torque in water is smaller than torque it experiences in air (see Zone 3 in Fig. 2). Thus, the torque

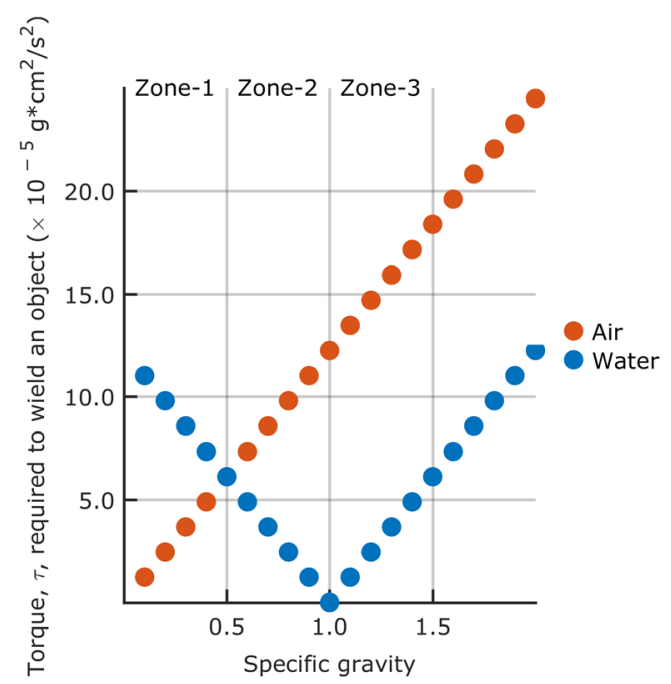

Fig. 2 Torque required to wield a rod in air and water as a function of its specific gravity (refer to the main text for details about Zones $1-3$ ). (Color figure online) 
required to wield an object in air increases with its density, but the torque required to wield an object in water can increase or decrease with its density in relation to the density of water.

Only two studies to date have examined if the properties of an object perceived through dynamic touch depends on its rotational inertia independent of the medium in which it is wielded. In one study (Pagano \& Donahue, 1999), the participants wielded aluminum rods of identical geometric dimensions (with and without attached masses) in air and water. The participants were not aware of the medium in which they were wielding the rods. In another study (Pagano \& Cabe, 2003), the participants wielded short and long aluminum rods in air and water and were aware of the medium in which they were wielding the rods. In both studies, rotational inertia informed the perception of the lengths of the rods, and the perceived lengths were invariant across changes in the medium (Pagano \& Cabe, 2003).

The goal of the present study was to examine if perception of the length of an object through dynamic touch depends on its rotational inertia, independent of the medium in which it is wielded. The participants wielded 12 different objects held in air or completely immersed in water and reported the perceived lengths of those objects. Each object consisted of a rod of a particular density with a particular number of stacked steel rings attached at a particular location along its length. The present study builds on two previous studies on the perception of the length of an object through dynamic touch in air and water (Pagano \& Cabe, 2003; Pagano \& Donahue, 1999) in that we used stimuli objects ranging from a fraction of $(0.86$ $\left.\mathrm{g} / \mathrm{cm}^{3}\right)$ to multiple times $\left(3.69 \mathrm{~g} / \mathrm{cm}^{3}\right)$ the density of water $\left(1.00 \mathrm{~g} / \mathrm{cm}^{3}\right)$ at $20^{\circ} \mathrm{C}$ ambient temperature. In this way, we manipulated the torque required for wielding the objects due to the differences in density of the objects in relation to the density of the medium. If the participants use rotational inertia of an object to perceive its length in both air and water, then the perceived length should remain invariant across changes in the medium. However, if the participants use the torque required to wield an object to perceive its length, then the perceived length of an object should vary with both object (density) and medium - in particular, objects should be perceived to be longer in air than in water, especially as density increases from values less than 1.0 to values greater than 1.0 (see Fig. 2).

\section{Method}

\section{Participants}

Six adult men and eight adult women (mean $\pm S D$ age $=23 \pm$ 0.9 years; range: $19-33$ years; all right-handed) participated in the present study. Each participant signed a consent form informing him or her of the purposes of the study, the procedures to be undergone, and the potential risks and benefits of participation. The present study was approved by the Institutional Review Board (IRB) at the University of Georgia (Athens, GA, USA).

\section{Stimuli rods}

The participants wielded 12 different objects with different rotational inertias. Each object consisted of a rod (length = $50.0 \mathrm{~cm}$, diameter $=1.2 \mathrm{~cm}$ ) of a particular density with a particular number of stacked steel rings (height $=0.2 \mathrm{~cm}$, inner radius $=0.7 \mathrm{~cm}$, outer radius $=1.7 \mathrm{~cm}$; mass $=14 \mathrm{~g}$ ) attached at a particular location along its length. We attached two rings on the pine wood rod (height $=0.4 \mathrm{~cm}$, mass $=28 \mathrm{~g}$ ), three rings on the maple wood rod (height $=0.6 \mathrm{~cm}$, mass $=42 \mathrm{~g}$ ), four rings on the hollow aluminum rod (height $=0.8 \mathrm{~cm}$, mass $=56 \mathrm{~g}$ ), and five rings on the solid aluminum rod (height $=1.0$ $\mathrm{cm}$, mass $=70 \mathrm{~g}$ ) (see Fig. 3 and Table 1). Table 2 reports the correlation matrix for the objects' mass $\left(\tau_{\text {air }}, \tau_{\text {water }} I_{1}\right.$, and $\left.I_{3}\right)$. We altered the distribution of mass (DM) of each rod by placing the rings on each rod at three different distances from the proximal end of the rod (DM-1: $25 \mathrm{~cm}$; DM-2: $35 \mathrm{~cm}$; DM-3: $45 \mathrm{~cm}$ ). To prevent water absorption, we coated the pine wood and maple wood rods with a thin layer of epoxy. To prevent water from entering the hollow aluminum rod, we sealed both its openings with epoxy. To prevent perception of the composition of a rod via cutaneous touch, we put a $15.0 \mathrm{~cm}$ rubber grip (inner diameter: $2.0 \mathrm{~cm}$; outer diameter: $3.4 \mathrm{~cm}$; mass: 7 g) on each rod (see Fig. 3). The densities of the objects (rods plus masses) ranged from a fraction of to multiple times the density of water at $20^{\circ} \mathrm{C}$ ambient temperature (pine wood: $0.86 \mathrm{~g} / \mathrm{cm}^{3}$; maple wood; $1.33 \mathrm{~g} / \mathrm{cm}^{3}$; hollow aluminum: $2.02 \mathrm{~g} / \mathrm{cm}^{3}$; solid aluminum: $3.69 \mathrm{~g} / \mathrm{cm}^{3}$ ).

\section{Setup}

We cut two 12-cm diameter circular openings - one at the near end and another at the far end - in the lids of two $84 \times$ $51 \times 34-\mathrm{cm}$ PVC containers and placed them on a table (see Fig. 4). The participant could insert his or her hand into a container through the opening in the lid at the near end, and an experimenter, S.A.B., could insert her hand into a container through the opening in the lid at the far end. One container was empty, and the other was filled three quarters with water. We placed a partition wall next to the containers oriented perpendicular to their lengths, and we hung black, opaque curtains from the ceiling to occlude the containers from the participant's view. We cut an opening in the curtain just above the top edge of the partition wall. The experimenter, S.A.B., could hand an object to the participant through the opening in the lid at the near end, from the nonoccluded side of this setup. She could change the container available to the participant after 


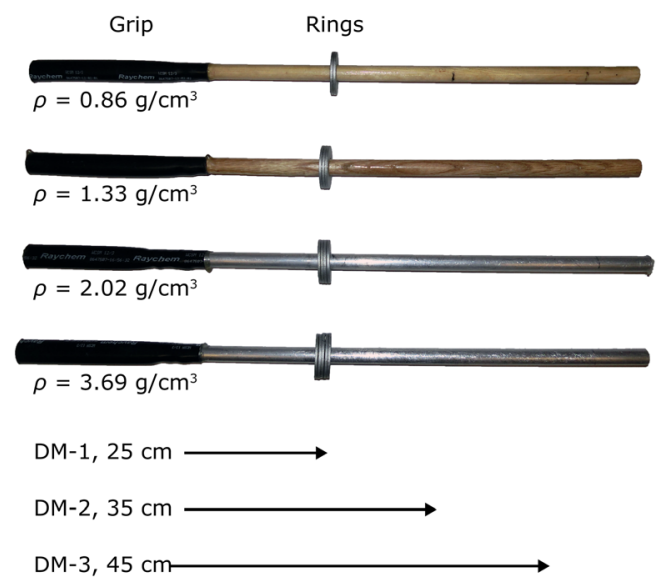

Fig. 3 Stimuli objects

having completed the trials for a given medium. The participant could grasp the object by inserting his or her right hand, first into the opening in the curtain above the partition wall at his or her chest level, and then into the empty or the water-filled container through the opening in the lid at the near end. The participant could report the perceived length of the object by sliding a pointer on a meter scale vaulted at his/her shoulder height. M.M. could read the measurement on the scale, but the participant could not.

\section{Procedures}

We tested each participant individually in a 45-60-min-long session. We conducted 72 trials, 36 each in air and water, three trials with each of the 12 objects in each of the two media. We blocked trials in each medium and randomized both the order of the medium and the sequence of trials in each medium. The participant wore a rubber dish-washing glove on his or her right hand. The participant stood on a platform with the partition wall on his or her side and inserted his or her right hand first into the opening in the curtain above the partition wall at his or her chest level and then into the empty or the waterfilled container through the opening in the lid at the near end. On each trial, S.A.B. handed the designated object to the participant, who grasped it with his or her dominant hand approximately $5 \mathrm{~cm}$ from its proximal end. The participant then wielded the object about his or her wrist and reported its perceived length on the meter scale by sliding the pointer. There were no restrictions on their wielding motion except that the participants were instructed to avoid hitting the walls of a container with an object. M.M. recorded the measurement on the meter scale, the participant handed the object back to S.A.B., and a new trial began.

\section{Results}

Table 6 in the Appendix reports the perceived lengths in centimeters of the 12 objects when wielded in air and water for each participant and averaged across all participants $(n=14)$. We conducted a 2 (medium) $\times 4$ (object) $\times 3$ (mass distribution) analysis of variance (ANOVA) on the perceived lengths of the 12 objects. We found main effects of object, $F(3,39)=$ $33.13, p<.001, \eta_{\mathrm{p}}^{2}=0.64$, and mass distribution, $F(2,26)=$ 27.14, $p<.001, \eta_{\mathrm{p}}{ }^{2}=0.67$. Follow-up $t$ tests with Bonferroni corrections revealed that the perceived lengths increased with the density of the objects and differed across all four objects

Table 1 Stimuli objects $(n=12)$

\begin{tabular}{|c|c|c|c|c|c|c|c|c|c|}
\hline $\begin{array}{l}\text { Composition } \\
\text { of the rod }\end{array}$ & $\begin{array}{l}\text { Mass } \\
\text { of the } \\
\text { rod }(g)\end{array}$ & $\begin{array}{l}\text { Mass } \\
\text { of the } \\
\text { attached } \\
\text { rings (g) }\end{array}$ & $\begin{array}{l}\text { Density } \\
\text { of the } \\
\text { object, } \\
\rho\left(\mathrm{g} / \mathrm{cm}^{3}\right)\end{array}$ & $\begin{array}{l}\text { Distribution } \\
\text { of mass }\end{array}$ & $\begin{array}{l}\text { Location } \\
\text { of the } \\
\text { attached } \\
\text { rings }(\mathrm{cm})\end{array}$ & $\tau_{\text {air }}\left(\mathrm{g} * \mathrm{~cm}^{2} / \mathrm{s}^{2}\right)^{\dagger}$ & $\tau_{\text {water }}\left(\mathrm{g} * \mathrm{~cm}^{2} / \mathrm{s}^{2}\right)^{\dagger}$ & $I_{1}\left(\mathrm{~g} * \mathrm{~cm}^{2}\right)^{\dagger}$ & $\underset{\dagger}{I_{3}}\left(\mathrm{~g} * \mathrm{~cm}^{2}\right)$ \\
\hline \multirow[t]{3}{*}{ Pine wood } & \multirow[t]{3}{*}{27} & \multirow[t]{3}{*}{28} & \multirow[t]{3}{*}{0.86} & DM-1 & 25 & $1,078,000$ & $-89,466$ & 30,673 & 710 \\
\hline & & & & DM-2 & 35 & $1,352,400$ & $-89,466$ & 44,745 & 633 \\
\hline & & & & DM-3 & 45 & $1,626,800$ & $-89,466$ & 64,322 & 656 \\
\hline \multirow[t]{3}{*}{ Maple wood } & \multirow[t]{3}{*}{44} & \multirow[t]{3}{*}{42} & \multirow[t]{3}{*}{1.33} & DM-1 & 25 & $1,685,600$ & 488,578 & 47,988 & 993 \\
\hline & & & & DM-2 & 35 & $2,097,200$ & 488,578 & 69,101 & 880 \\
\hline & & & & DM-3 & 45 & $2,508,800$ & 488,578 & 98,466 & 915 \\
\hline \multirow[t]{3}{*}{ Hollow aluminum } & \multirow[t]{3}{*}{75} & \multirow[t]{3}{*}{56} & \multirow[t]{3}{*}{2.22} & DM-1 & 25 & $2,567,600$ & $1,341,022$ & 71,214 & 434 \\
\hline & & & & DM-2 & 35 & $3,116,400$ & $1,341,022$ & 104,070 & 670 \\
\hline & & & & DM-3 & 45 & $3,665,200$ & $1,341,022$ & 148,070 & 970 \\
\hline \multirow[t]{3}{*}{ Solid aluminum } & \multirow[t]{3}{*}{171} & \multirow[t]{3}{*}{70} & \multirow[t]{3}{*}{3.69} & DM-1 & 25 & $4,723,600$ & $3,467,466$ & 141,420 & 2720 \\
\hline & & & & DM-2 & 35 & $5,409,600$ & $3,467,466$ & 176,640 & 2490 \\
\hline & & & & DM-3 & 45 & $6,095,600$ & $3,467,466$ & 225,530 & 2610 \\
\hline
\end{tabular}

$\dagger$ Values of a $3 \times 3$ inertia tensor matrix for each object were clulated for rotations about the wrist with the assumptions of a 5 -m distance between the location of grasp and the proximal end of the object, a $6-\mathrm{cm}$ distance between the wrist and the longitudinal axis of the rod, and negligible contribution of the mass of the epoxy and rubber grip. The pine wood, maple wood, and solid aluminum rods were treated as solid cylinders; the hollow aluminum rod and the attached masses were treated as hollow cylinders. Eigenvalues were then calculated by diagonalizing the $3 \times 3$ inertia tensor matrix using the MATLAB function "eig (A)" 
Table 2 Correlation matrix for the objects' mass, $\tau_{\text {air }}, \tau_{\text {water, }} I_{1}$, and $I_{3}$

\begin{tabular}{llllll}
\hline & Mass & $\tau_{\text {air }}$ & $\tau_{\text {water }}$ & $I_{1}$ & $I_{3}$ \\
\hline Mass & 1.00 & & & & \\
$\tau_{\text {air }}$ & 0.97 & 1.00 & & & \\
$\tau_{\text {water }}$ & 1.00 & 0.96 & 1.00 & & \\
$I_{1}$ & 0.89 & 0.98 & 0.89 & 1.00 & \\
$I_{3}$ & 0.90 & 0.87 & 0.91 & 0.81 & 1.00 \\
\hline
\end{tabular}

(mean $\pm S E M$ values: pine wood $=33.5 \pm 0.8 \mathrm{~cm}$; maple wood $=35.8 \pm 0.8 \mathrm{~cm}$; solid aluminum $=39.2 \pm 0.9 \mathrm{~cm}$; hollow aluminum $=42.7 \pm 1.0 \mathrm{~cm}$; all corrected $p \mathrm{~s}<.05)$. The perceived lengths also tended to increase with the distance of the attached rings from the point of rotation. The participants perceived DM-3 $(40.1 \pm 0.9 \mathrm{~cm})$ longer than either DM-2 $(37.1 \pm$ $0.8 \mathrm{~cm})$ or DM-1 $(36.2 \pm 0.8 \mathrm{~cm}$; both corrected $p \mathrm{~s}<.05$; see Fig. 5 and Table 3). However, the main effect of medium was not significant. There was no difference between the perceived lengths across the two media (air $=38.8 \pm 0.7 \mathrm{~cm}$; water = $36.8 \pm 0.7 \mathrm{~cm}$ ). There was also an interaction of medium and object, $F(3,39)=3.52, p<.05$, but $t$ tests with Bonferroni corrections revealed no differences in the perceived lengths for any of the objects across the two media (see Fig. 5 and Table 3). The ANOVA revealed no other significant effects. In other words, the perceived lengths varied with changes in the factors that influenced $I_{1}$ and $I_{3}$ (i.e., density of the objects and their distribution of mass) but not with changes in the factors that influenced torque (i.e., density of the objects and the medium; see Table 1). Therefore, we further examined if the perceived lengths of the 12 objects depended on their rotational inertia $\left(I_{1}\right.$ and $\left.I_{3}\right)$.

In previous studies (Pagano \& Cabe, 2003; Pagano \& Donahue, 1999), a single-valued function of $I_{1}$ and $I_{3}$ predicted the perceived lengths of rods when wielded in air and water. Here, the connotation of a single-valued function implies that the perception is supported by detection of a single informational variable. If perception of lengths of objects by dynamic touch is a single-valued function of $I$, a given value should give rise to a given perceived length, and a given perceived length should be brought about by a given value of $I$. In other words, the perception is direct (Jacobs \& Michaels, 2007). We examined the relative contributions of $\log I_{1}$ and $\log I_{3}$ to $\log l$ (i.e., $\log [$ perceived length]) to obtain similar power functions, and whether the lengths of the 12 objects yielded by the obtained power functions predicted the perceived lengths of those objects averaged across all participants $(n=14)$ when wielded in air and water. Additionally, we examined the relationship between the perceived lengths of the 12 objects and the rotational inertia of those objects.

A multiple regression revealed that the coefficients of $I_{1}$ and $I_{3}$ were (+) 0.197 and (-) 0.010 , respectively, with $R^{2}=$ 0.917 when the objects were wielded in air (see Table 3). A multiple regression revealed that the coefficients of $I_{1}$ and $I_{3}$ were (+) 0.151 and (-) 0.001 , respectively, with $R^{2}=0.906$ when the objects were wielded in water (see Table 3 ). Accordingly, the power functions of $I_{1}$ and $I_{3}$ yielding the lengths of the 12 objects for wielding in air and water were, $l_{\text {air }}=4.341\left(I_{1}^{0.197} \times I_{3}{ }^{-0.010}\right)$ and $l_{\text {water }}=6.609\left(I_{1}{ }^{0.151} \times I_{3}{ }^{-}\right.$ $\left.{ }^{0.001}\right)$, respectively, similar to those found in previous studies (Fitzpatrick et al., 1994; Pagano \& Cabe, 2003; Pagano \& Donahue, 1999). The positive exponent on $I_{1}$ and negative exponent on $I_{3}$ show that the perceived length of an object increases as that object increasingly (and selectively) resists rotation about an axis perpendicular to its longitudinal axis. Moreover, the scaling relationship between the perceived length of an object and its rotational inertia is nearly identical when it is wielded in air and water.

A simple regression revealed that the lengths of the 12 objects yielded by the power function of $I_{1}$ and $I_{3}$ obtained for wielding in air, $l_{\text {air }}=4.341\left(I_{1}^{0.197} \times I_{3}^{-0.010}\right)$ predicted the perceived lengths of those objects when wielded in air with $R^{2}$ $=0.917$ (see Fig. 6a and Table 4). Another simple regression revealed that the lengths of the 12 objects yielded by the power function of $I_{1}$ and $I_{3}$ obtained for wielding in water, $l_{\text {water }}=$ $6.609\left(I_{1}^{0.151} \times I_{3}^{-0.001}\right)$, predicted the perceived lengths of those objects when wielded in water with $R^{2}=0.906$ (see Fig.

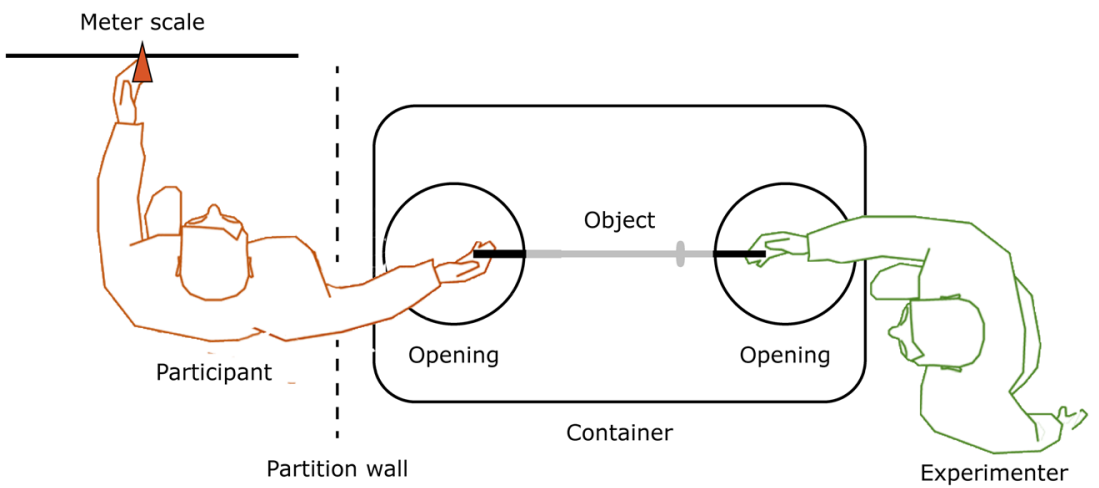

Fig. 4 Experimental setup from the top view (the experimenter is handing an object to a participant; the object is inside the container and is visible through the transparent lid) 

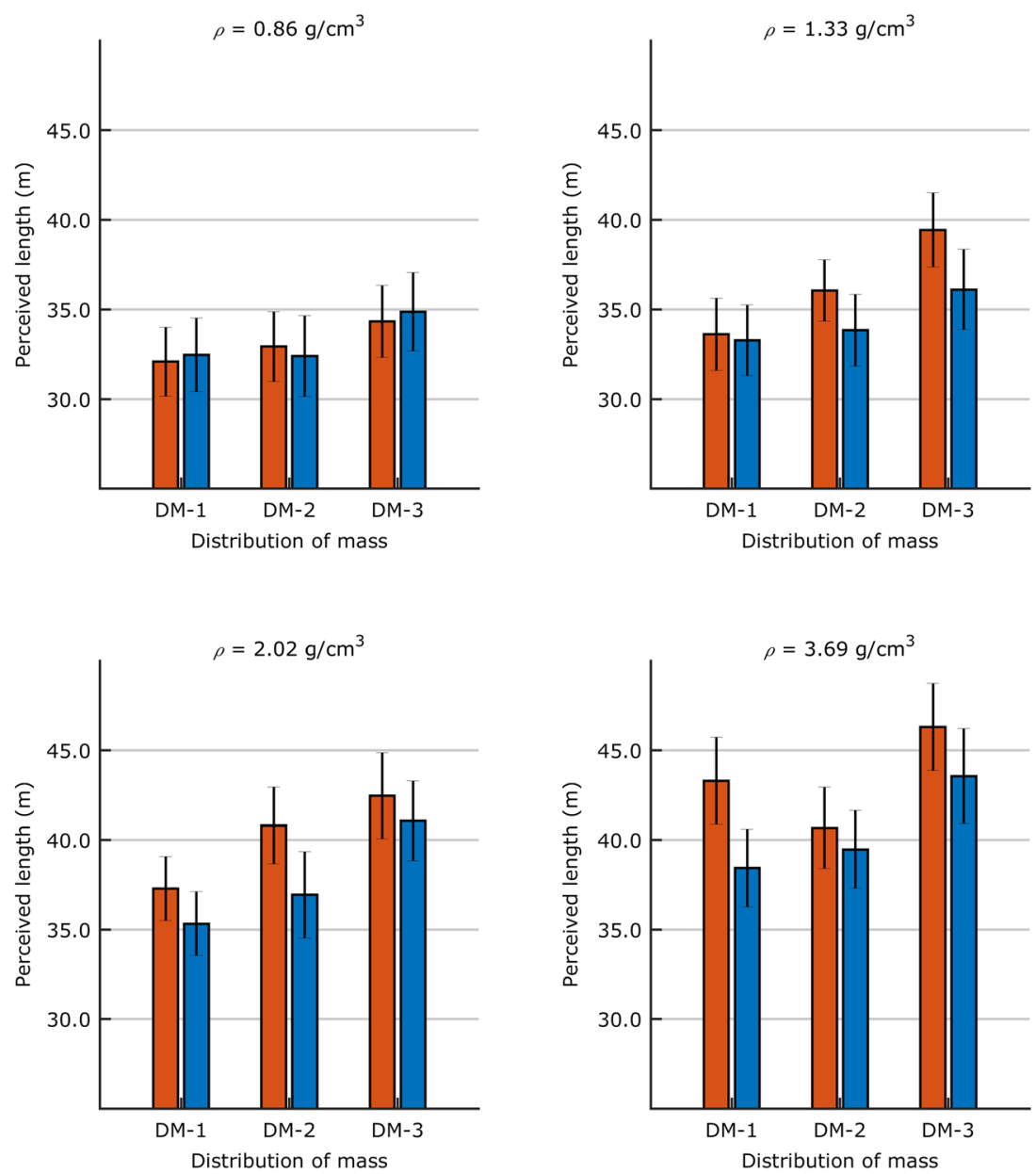

Fig. 5 Perceived lengths of the 12 objects averaged across all participants $(n=14)$ when wielded in air and water (error bars indicate the SEM). (Color figure online)

$6 \mathrm{~b}$ and Table 4). To strengthen the claim that the information supporting perception of length of an object is invariant across the two media - air and water-we compared the perceived lengths yielded by the power function obtained for water with perceived lengths reported by participants in air, and vice versa. The lengths of the 12 objects yielded by the power function of $I_{1}$ and $I_{3}$ obtained for wielding in water predicted the perceived lengths of those objects when wielded in air with $R^{2}=0.915$ (see Table 5). Similarly, the lengths of the 12 objects yielded by the power function of $I_{1}$ and $I_{3}$ obtained for wielding in air predicted the perceived lengths of those objects when wielded in water with $R^{2}=0.911$ (see Table 5). Such results suggest that perception of length by dynamic touch depends on detection of $I$ regardless of whether the object is wielded in water or air. In other words, such results suggest that the haptic information for perception of

Table 3 Outcomes of multiple regressions examining the relative contributions of $\log I_{1}$ and $\log I_{3}$ in $\log l$ of the 12 objects averaged across all participants $(n=14)$ when wielded in air and water

\begin{tabular}{|c|c|c|c|c|c|c|c|}
\hline Medium & $F(2,9)$ & $R^{2}$ & $p$ & & Estimate $\pm S E M$ & $t$ & $p$ \\
\hline \multirow[t]{3}{*}{ Air } & \multirow[t]{3}{*}{58.61} & \multirow[t]{3}{*}{0.913} & \multirow[t]{3}{*}{$<.001$} & Intercept & $0.638 \pm 0.088$ & 7.257 & $<.001$ \\
\hline & & & & Coefficient of $I_{1}$ & $0.197 \pm 0.025$ & 7.832 & $<.001$ \\
\hline & & & & Coefficient of $I_{3}$ & $-0.105 \pm 0.025$ & -0.422 & 0.683 \\
\hline \multirow[t]{3}{*}{ Water } & \multirow[t]{3}{*}{49.09} & \multirow[t]{3}{*}{0.897} & \multirow[t]{3}{*}{$<.001$} & Intercept & $0.820 \pm 0.757$ & 10.827 & $<.001$ \\
\hline & & & & Coefficient of $I_{1}$ & $0.151 \pm 0.217$ & 6.942 & $<.001$ \\
\hline & & & & Coefficient of $I_{3}$ & $-0.001 \pm 0.215$ & -0.065 & 0.950 \\
\hline
\end{tabular}

Significant $p$ values are indicated in boldface 

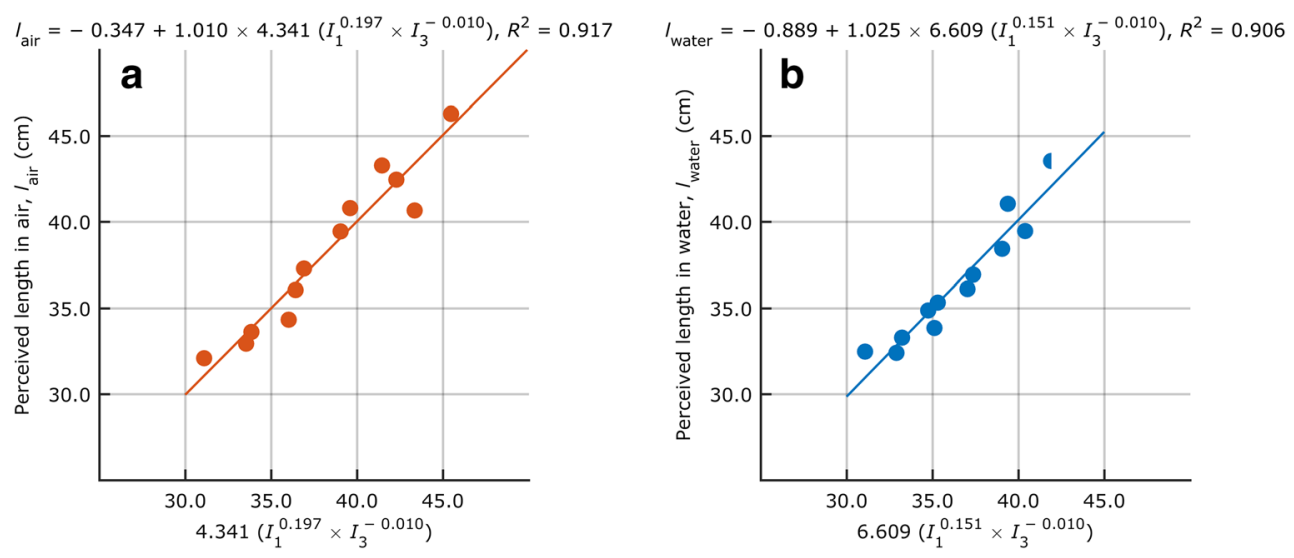

Fig. 6 Relationships between the lengths of the 12 objects yielded by the power function obtained from $I_{1}$ and $I_{3}$ and the perceived lengths of those objects averaged across all participants $(n=14)$ when wielded in (a) air and (b) water

length by dynamic touch is invariant across changes in the medium.

Additionally, a simple regression examining the relationship between the perceived lengths of the 12 objects when wielded in air and water ( $n=168,14$ participants $\times 12$ objects) yielded a significant regression equation, $F(1,166)=226.8, p$ $<.001$, with $R^{2}=0.575$. The perceived length of each object when wielded in water was equal to $8.854+0.720$ times the perceived length of that object when wielded in air, in centimeters (see Fig. 7). The linear relationship depicted in Fig. 7, which is also referred to as a Brinley plot (Brinley, 1965), suggests a common mechanism for the perception of the properties of an object in different media (cf. Hajnal, Fonseca, Harrison, et al., 2007).

\section{Discussion}

The goal of the present study was to examine if perception of the length of an object through dynamic touch depends on its rotational inertia, independent of the medium in which it is wielded. The participants $(n=14)$ wielded 12 different objects held in air or completely immersed in water and reported perceived lengths of those objects. Each object consisted of a rod of a particular density with a particular number of stacked steel rings attached at a particular location along its length. A single-valued function of the major eigenvalue, $I_{1}$, and the minor eigenvalue, $I_{3}$, of the rotational inertia, $I$, of the 12 objects predicted the perceived lengths of those objects in both air and water, and the perceived lengths remained invariant across the two media. These results support the hypothesis that the informational support for perception of the length of an object through dynamic touch is invariant across changes in the medium. We discuss these results in relation to those of previous studies, as well as their implications for future research.

Consistent with the findings of previous studies (Pagano \& Cabe, 2003; Pagano \& Donahue, 1999), in the present study, the perceived lengths of the objects remained invariant across the two media - air and water. Pagano and Cabe (2003) explained the physical basis of such invariance in dynamic touch. Cyclic movements in wielding actions allow the extraction of rotational inertia independent of the torque required to counter all other forces acting on an object. To initiate the rotational movement of an object about an axis, $i$, with angular acceleration, $\omega_{i}$, torque, $\tau$, is required to overcome the rotational inertia of the object, $I_{\mathrm{i}}$, and counter the weight of the object, $\tau_{\mathrm{g}}$, and the drag acting on it while it is in motion, $\tau_{\mathrm{d}}$ :

$\tau_{\mathrm{i}}=I_{\mathrm{i}} \omega_{\mathrm{i}}+\tau_{\mathrm{g}}+\tau_{\mathrm{d}}$

Table 4 Outcomes of multiple regressions examining if the lengths of the 12 objects yielded by the power function obtained from $I_{1}$ and $I_{3}$ predicted the perceived lengths of those objects averaged across all participants $(n=14)$ when wielded in air and water

\begin{tabular}{|c|c|c|c|c|c|c|c|}
\hline Medium & $F(1,10)$ & $R^{2}$ & $p$ & & Estimate $\pm S E M$ & $t$ & $p$ \\
\hline \multirow[t]{2}{*}{ Air } & 122.8 & 0.917 & $<.001$ & Intercept & $-0.374 \pm 3.506$ & -0.099 & 0.923 \\
\hline & & & & Coefficient of $F_{\text {air }}$ & $1.010 \pm 0.091$ & 11.082 & $<.001$ \\
\hline \multirow[t]{2}{*}{ Water } & 106.8 & 0.906 & $<.001$ & Intercept & $-0.889 \pm 3.629$ & -0.245 & 0.811 \\
\hline & & & & Coefficient of $F_{\text {water }}$ & $-0.889 \pm 3.629$ & 10.334 & $<.001$ \\
\hline
\end{tabular}

Significant $p$ values are indicated in boldface 
Table 5 Outcomes of multiple regressions examining if the lengths of the 12 objects yielded by the power function obtained from $I_{1}$ and $I_{3}$ predicted the perceived lengths of those objects averaged across all participants $(n=14)$ when wielded in a different medium

\begin{tabular}{|c|c|c|c|c|c|c|c|}
\hline Medium & $F(1,10)$ & $R^{2}$ & $p$ & & Estimate $\pm S E M$ & $t$ & $p$ \\
\hline \multirow[t]{2}{*}{ Air } & 119.8 & 0.915 & $<.001$ & Intercept & $-10.435 \pm 4.466$ & -2.333 & .042 \\
\hline & & & & Coefficient of $F_{\text {water }}$ & $1.336 \pm 0.112$ & 10.947 & $<.001$ \\
\hline \multirow[t]{2}{*}{ Water } & 113.4 & 0.911 & $<.001$ & Intercept & $6.8032 \pm 2.803$ & 2.427 & .036 \\
\hline & & & & Coefficient of $F_{\text {air }}$ & $0.776 \pm 0.073$ & 10.650 & $<.001$ \\
\hline
\end{tabular}

Significant $p$ values are indicated in boldface

At the end of the arc, to initiate the rotational movement of the object in the opposite direction with angular acceleration, $\omega_{\mathrm{i}}$, torque, $\tau_{\mathrm{i}}$, is required to overcome the rotational inertia of the object, $I_{\mathrm{i}}$, but is now aided by the weight of the object, $\tau_{\mathrm{g}}$, and the drag acting on it while in motion, $\tau_{\mathrm{d}}$ :

$\tau_{\mathrm{i}}=I_{\mathrm{i}} \omega-\tau_{\mathrm{g}}-\tau_{\mathrm{d}}$.

Cyclic movements in wielding actions isolate information about the torque required to wield an object due its rotational inertia:

$\tau_{\mathrm{i}}=I_{\mathrm{i}} \omega$.

The denser the medium, the greater the torque required to counter the forces acting on a wielded object other than the forces due to its inertia, and thus the smaller the frequency and angular velocity of cyclic movements in wielding actions. However, we could not explicitly test these hypotheses because we did not measure the frequency and angular velocity of cyclic movements in wielding actions. These are interesting hypotheses for future research.

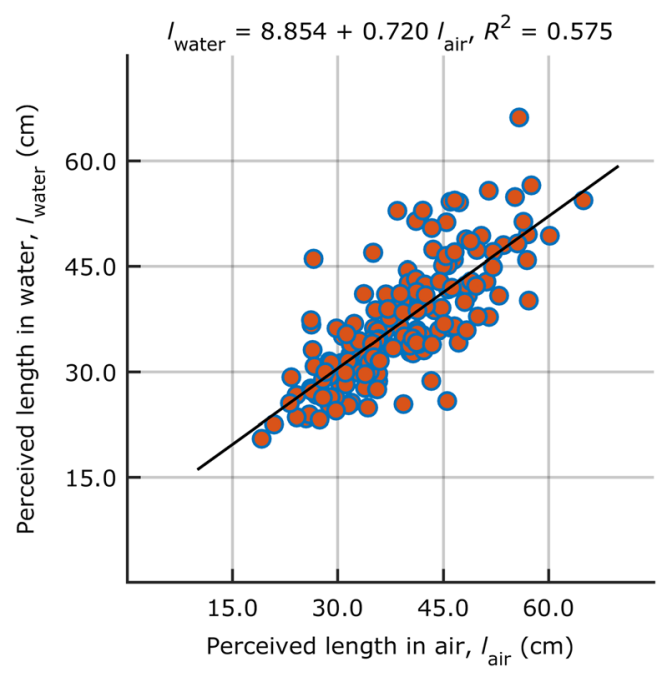

Fig. 7 Relationship between the perceived lengths of the 12 objects for each participant when wielded in air and water $(n=168,14$ participants $\times$ 12 objects)
The present study differed from the two previous studies on the perception of the length of an object through dynamic touch in air and water (Pagano \& Cabe, 2003; Pagano \& Donahue, 1999) in three methodological details: (1) We used rods of identical dimensions (length, $l$ $=50 \mathrm{~cm}$, radius, $r=0.6 \mathrm{~cm}$ ) to minimize any differences in the drag acting on them while they were in motion in water. (2) We used objects consisting of rods that varied in density from a fraction of $\left(0.86 \mathrm{~g} / \mathrm{cm}^{3}\right)$ to multiple times $\left(3.69 \mathrm{~g} / \mathrm{cm}^{3}\right)$ that of water $\left(1.00 \mathrm{~g} / \mathrm{cm}^{3}\right)$ at $20^{\circ} \mathrm{C}$ ambient temperature, to manipulate the torque required for wielding the objects due to the differences in the density of objects in relation to the density of the medium. (3) We asked the participants to wield the objects horizontally and completely immersed in water to account for the contribution of buoyancy on the torque required to wield those objects in water.

The perceived lengths of the objects increased with the density of the objects (pine to maple wood to hollow to solid aluminum) and with the location of the attached mass moving toward the distal end of the rod (DM-1 to DM-2 to DM-3) in both air and water. The density and the distribution of mass together determined the rotational inertia of the objects and thus contributed to the perception of the lengths of those objects. This finding is consistent with those of previous studies (Pagano \& Cabe, 2003; Pagano \& Donahue, 1999; Solomon \& Turvey, 1988; Solomon et al., 1989; Turvey et al., 1992), though it will be important in future research to use an even wider range of object densities. Previous studies have also documented whether and how perception of lengths of objects wielded in air become more tightly constrained by $I_{1}$ and $I_{3}$ with practice or feedback (e.g., Wagman, Shockley, Riley, \& Turvey, 2001). Whether similar or identical changes would occur with practice or feedback for wielding an object in water is a topic for future research.

Detection of $I$ by dynamic touch yields perception of length that is neither "absolutely scaled" nor "relatively scaled." Absolutely scaled judgments imply no discrepancy between the perceived and actual dimensions, and relatively scaled judgments imply a comparable order of 
correspondence but an arbitrary relationship between the perceived and actual dimensions. Instead, detection of an invariant yields judgments (such as those reported in the present study) that Bingham (1993) referred to as "definitely scaled." Definitely scaled judgments lie within a range of marginal tolerance of the actual dimensions of an object. Further, definitely-scaled judgments rely on information that is more precise than for relatively scaled judgments but that is less precise than for absolutely scaled judgments. Interestingly, in the present study, the perceived lengths of the 12 objects never exceeded the actual length of those objects $(50 \mathrm{~cm})$, although the difference between the perceived length and the actual length decreased with the density of the objects (i.e., the perceived length increased with the density of the objects). In previous studies (Carello, Fitzpatrick, Flascher, \& Turvey, 1998; Pagano \& Cabe, 2003), perceived lengths of wooden and aluminum rods of comparable dimensions did not exceed their actual lengths, but that of steel rods of comparable dimensions did. Multiple combinations of material composition and dimensions can yield comparable values of inertia. This pattern of observations suggests that the perception of the length of an object through dynamic touch may correspond more closely to the actual dimensions for objects of certain combinations of material composition and distributions of mass. The determination of this correspondence has implications for the design and functionality of handheld precision implements and thus should be a topic for future experimental investigation.

Another question concerns the perception of the properties of the medium itself through dynamic touch. Wielding actions generate two distinct patterns of haptic stimulation-one contributing to the perception of the properties of the wielded object and the other contributing to the perception of the properties of the medium (see Carello, Fitzpatrick, \& Turvey, 1992). We hypothesize that the kinetics and kinematics of movements in wielding actions directed at the perception of the properties of the wielded object and the properties of the wielding medium differ significantly. Wielding actions with cyclic movements of a threshold frequency may be required to perceive the rotational inertia of an object. In contrast, wielding actions with movements of a threshold amplitude may be required to perceive the torque experienced by the probe in motion in a medium. These hypotheses merit experimental investigation.

On the one hand, the perception of the properties of an object (length, width, and shape) through dynamic touch is independent of the properties of the medium (Pagano \& Cabe, 2003; Pagano \& Donahue, 1999). On the other hand, the perception of the properties of the medium by probing it may depend on the length, width, and shape of the probe and the orientation of the probe relative to the direction and the plane of its motion in the medium. For example, it might be difficult to identify the properties of a medium by probing it with a knife along the plane parallel to the edge of the knife. This difficulty arises because of insufficient perceptual information given that the drag acting on an object in motion in a given medium is directly proportional to the projected surface area of an object in contact with the medium perpendicular to the direction of its motion. This reasoning also explains why it is difficult to perceive the properties of a medium by probing it with a thin object such as a hairpin.

J. J. Gibson (Gibson, 1966, 1979) proposed that perception is an epistemic relationship between organisms and their environment. Organisms must not only perceive in order to act but also act in order to perceive. From this perspective, perception of a property is a function of detection of an invariant stimulation pattern that specifies that property. An established body of scientific literature suggests that, in the context of perceiving the properties of objects through dynamic touch (wielding), rotational inertia is one such invariant quantity (see Turvey \& Carello, 2011). Dynamic touch supports the proposition that "the stimulus information from wielding can only be an invariant of the changing flux of stimulation in the muscles and tendons, an extero specific invariant in this play of forces" (Gibson, 1966, p. 127). The present results extend support for Gibson's hypothesis on the role of invariant mechanical quantities in active perception and for the proposition that rotational inertia is one such invariant mechanical quantity in the perception of the properties of objects through dynamic touch.

A central hypothesis is that the information acquired through dynamic touch is in the form of patterns of deformation in body tissue (Gibson, 1966; Turvey \& Carello, 2011; Turvey \& Fonseca, 2014). Tissue deformations result from the forces generated by haptic manipulations and are expressed through strain and rate of change in strain. Body tissue constitutes the medium for the distribution of mechanical energy in the body similar to how air and water constitutes the media for the distribution of light, sound, and chemical energy. Thus, deformations in body tissue must dictate both the kinetics and kinematics of movements in wielding objects. The latter requires in-depth attention if we want to exploit dynamic touch and its implications for instrumental behavior, such as tool use in artificial agents, including robots.

Author contributions Conceptualization, M.M.; Methodology, M.M.; Investigation, M.M. and S.A.B.; Formal analysis, M.M. and J.B.W.; Writing - original draft, M.M., S.A.B., and D.M.F.; Writing-review \& editing, M.M., S.A.B., J.B.W., D.M.F., and K.M.N. 


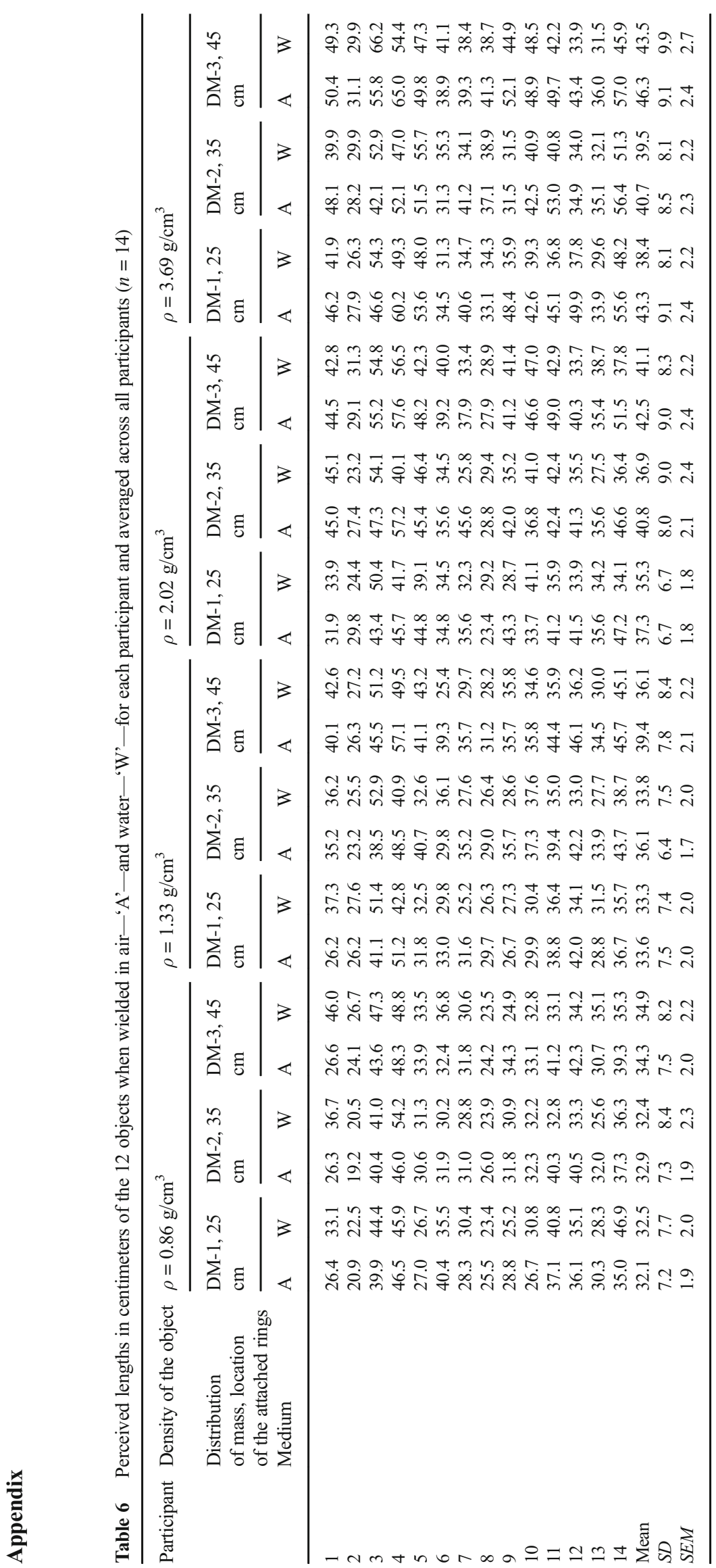




\section{References}

Bingham, G. P. (1993). Perceiving the size of trees: Form as information about scale. Journal of Experimental Psychology: Human Perception and Performance, 19(6), 1139-1161. doi:10.1037/ 0096-1523.19.6.1139

Brinley, J. F. (1965). Cognitive sets, speed and accuracy of performance in the elderly. In A. T. Welford \& J. E. Birren (Eds.), Behavior, aging, and the nervous system (pp. 114-149). Springfield, IL: Charles C. Thomas.

Burton, G., \& Turvey, M. T. (1990). Perceiving the lengths of rods that are held but not wielded. Ecological Psychology, 2(4), 295-324. doi:10. 1207/s15326969eco0204 1

Burton, G., Turvey, M. T., \& Solomon, H. Y. (1990). Can shape be perceived by dynamic touch? Perception \& Psychophysics, 48(5), 477-487. doi:10.3758/BF03211592

Carello, C., Fitzpatrick, P., Domaniewicz, I., Chan, T.-C., \& Turvey, M. T. (1992). Effortful touch with minimal movement. Journal of Experimental Psychology: Human Perception and Performance, 18(1), 290-302. doi:10.1037/0096-1523.18.1.290

Carello, C., Fitzpatrick, P., \& Turvey, M. T. (1992). Haptic probing: Perceiving the length of a probe and the distance of a surface probed. Perception \& Psychophysics, 51(6), 580-598. doi:10.3758/ BF03211655

Carello, C., \& Turvey, M. T. (2000). Rotational invariance and dynamic touch. In M. A. Heller (Ed.), Touch, representation and blindness (pp. 27-66). New York, NY: Oxford University Press.

Cooper, M. M., Carello, C., \& Turvey, M. T. (2000). Perceptual independence of whole length, partial length, and hand position in wielding a rod. Journal of Experimental Psychology: Human Perception and Performance, 26(1), 74-85. doi:10.1037/0096-1523.26.1.74

Denny, M. W. (1993). Air and water in the biology and physics of life's media. Princeton, NJ: Princeton University Press.

Fitzpatrick, P., Carello, C., \& Turvey, M. T. (1994). Eigenvalues of the inertia tensor and exteroception by the "muscular sense". Neuroscience, 60(2), 551-568. doi:10.1016/0306-4522(94)90264-X

Gibson, J. J. (1966). The senses considered as perceptual systems. Boston, MA: Houghton Mifflin.

Gibson, J. J. (1979). The ecological approach to visual perception. Boston, MA: Houghton Mifflin.

Hajnal, A., Fonseca, S., Harrison, S., Kinsella-Shaw, J. M., \& Carello, C. (2007). Comparison of dynamic (effortful) touch by hand and foot. Journal of Motor Behavior, 39(2), 82-88. doi:10.3200/JMBR.39.2. $82-88$

Hajnal, A., Fonseca, S., Kinsella-Shaw, J. M., Silva, P., Carello, C., \& Turvey, M. T. (2007). Haptic selective attention by foot and by hand. Neuroscience Letters, 419(1), 5-9. doi:10.1016/j.neulet.2007.03.042

Jacobs, D. M., \& Michaels, C. F. (2007). Direct learning. Ecological Psychology, 19(4), 321-349. doi:10.1080/10407410701432337

Pagano, C. C., \& Cabe, P. A. (2003). Constancy in dynamic touch: Length perceived by dynamic touch is invariant over changes in media. Ecological Psychology, 15(1), 1-17. doi:10.1207/ S15326969ECO1501_01

Pagano, C. C., \& Donahue, K. G. (1999). Perceiving the lengths of rods wielded in different media. Perception \& Psychophysics, 61(7), 1336-1344. doi:10.3758/BF03206184
Pagano, C. C., Kinsella-Shaw, J. M., Cassidy, P. E., \& Turvey, M. T. (1994). Role of the inertia tensor in haptically perceiving where an object is grasped. Journal of Experimental Psychology: Human Perception and Performance, 20(2), 276-285. doi:10.1037/00961523.20.2.276

Pagano, C. C., \& Turvey, M. T. (1992). Eigenvectors of the inertia tensor and perceiving the orientation of a hand-held object by dynamic touch. Perception \& Psychophysics, 52(6), 617-624. doi:10.3758/ BF03211699

Palatinus, Z., Carello, C., \& Turvey, M. T. (2011). Principles of partwhole selective perception by dynamic touch extend to the torso. Journal of Motor Behavior, 43(2), 87-93. doi:10.1080/00222895. 2010.538767

Peck, A. J., Jeffers, R. G., Carello, C., \& Turvey, M. T. (1996). Haptically perceiving the length of one rod by means of another. Ecological Psychology, 8(3), 237-258. doi:10.1207/s15326969eco0803_3

Shaw, R. (2001). Processes, acts, and experiences: Three stances on the problem of intentionality. Ecological Psychology, 13(4), 275-314. doi:10.1207/S15326969ECO1304_02

Solomon, H. Y., \& Turvey, M. T. (1988). Haptically perceiving the distances reachable with hand-held objects. Journal of Experimental Psychology: Human Perception and Performance, 14(3), 404- 427. doi:10.1037/0096-1523.14.3.404

Solomon, H. Y., Turvey, M. T., \& Burton, G. (1989). Perceiving extents of rods by wielding: Haptic diagonalization and decomposition of the inertia tensor. Journal of Experimental Psychology: Human Perception and Performance, 15(1), 58-68. doi:10.1037/00961523.15.1.58

Turvey, M. T. (1996). Dynamic touch. American Psychologist, 51(11), 1134-1152. doi:10.1037/0003-066X.51.11.1134

Turvey, M. T., Burton, G., Amazeen, E. L., Butwill, M., \& Carello, C. (1998). Perceiving the width and height of a hand-held object by dynamic touch. Journal of Experimental Psychology: Human Perception and Performance, 24(1), 35-48. doi:10.1037/00961523.24.1.35

Turvey, M. T., Burton, G., Pagano, C. C., Solomon, H. Y., \& Runeson, S. (1992). Role of the inertia tensor in perceiving object orientation by dynamic touch. Journal of Experimental Psychology: Human Perception and Performance, 18(3), 714-727. doi:10.1037/00961523.18.3.714

Turvey, M. T., \& Carello, C. (2011). Obtaining information by dynamic (effortful) touching. Philosophical Transactions of the Royal Society of London B: Biological Sciences, 366(1581), 3123-3132. doi:10. 1098/rstb.2011.0159

Turvey, M. T., \& Fonseca, S. T. (2014). The medium of haptic perception: A tensegrity hypothesis. Journal of Motor Behavior, 46(3), 143187. doi:10.1080/00222895.2013.798252

Wagman, J. B., Langley, M. D., \& Higuchi, T. (2017). Turning perception on its head: Cephalic perception of whole and partial length of a wielded object. Experimental Brain Research, 235(1), 153-167. doi:10.1007/s00221-016-4778-2

Wagman, J. B., Shockley, K., Riley, M. A., \& Turvey, M. T. (2001). Attunement, calibration, and exploration in fast haptic perceptual learning. Journal of Motor Behavior, 33(4), 323-327. doi:10. 1080/00222890109601917 